\title{
Growth Hormone Deficiency Is Not Associated with Impaired Vagal Cholinergic Nervous System Activity in Children
}

\author{
AARON HANUKOGLU, STUART CHALEW, AND A. AVINOAM KOWARSKI
}

Department of Pediatrics, University of Maryland School of Medicine, Baltimore, Maryland 21201

\begin{abstract}
Central cholinergic mechanisms mediate release of growth hormone $(\mathrm{GH})$ as well as peripheral secretion of pancreatic polypeptide (PP). To determine if impaired ability to secrete GH is associated with defective PP response, we studied the PP, epinephrine, and norepinephrine responses to insulin-induced hypoglycemia in $\mathbf{3 1}$ children evaluated for $\mathbf{G H}$ deficiency by insulin-arginine stimulation (IATT) and 24-h integrated concentrations of GH (IC-GH). Eleven patients had normal GH by IATT and IC-GH (controls), 10 patients had normal GH by IATT but subnormal IC-GH, 10 patients had GH deficiency by both IATT and IC-GH. PP levels peaked at the time of glucose nadir, and remained elevated for $\mathbf{2 0}$ min thereafter. The peak PP and incremental PP change from baseline were not significantly different among the three groups. The log peak PP response was inversely correlated with the glucose nadir $(r=-0.5, p<0.005)$. Peak PP levels were also significantly correlated with the peak epinephrine levels $(r=0.6, p<0.001)$ but not with norepinephrine. Our findings suggest that 1 ) $\mathrm{GH}$ deficiency disorders are not associated with impaired vagal cholinergic response to hypoglycemia; 2) in children the magnitude of $P P$ response is inversely related to the degree of hypoglycemia; and 3 ) the peripheral hormonal manifestation of autonomic nervous system responses to hypoglycemia as measured by PP and epinephrine levels are closely correlated. (Pediatr Res 24: 574-576, 1988)
\end{abstract}

\section{Abbreviations}

GH, growth hormone

$\mathbf{P P}$, pancreatic polypeptide

$\mathrm{E}$, epinephrine

NE, norepinephrine

IC, integrated concentration

hPP, human PP

GHND, GH neurosecretory dysfunction

GHD, GH deficiency

Central cholinergic mechanisms mediate $\mathrm{GH}$ release $(1,2)$ as well as secretion of PP $(3,4)$. Cholinergic agonists potentiate the secretion of both GH and PP and conversely antagonists of cholinergic muscarinic receptors such as pirenzepine and atropine blunt the secretion of these hormones $(1,5)$. We tested the hypothesis that children with impaired GH secretion might also have impairment of vagal cholinergic activity, manifested by

Received April 22, 1988; accepted June 29, 1988.

Correspondence and reprint requests Dr. Aaron Hanukoglu, University of Maryland School of Medicine, Division of Pediatric Endocrinology, BRB 10-047, 655 West Baltimore Street, Baltimore, MD 21201. deficient PP secretion. During insulin-induced hypoglycemia which is a potent stimulant for PP and GH secretion $(3,6-8)$, we evaluated the responses of autonomic nervous system activity in children with $\mathrm{GH}$ deficiency syndromes.

\section{SUBJECTS AND METHODS}

Patients in this study were referred for evaluation of short stature. None of the patients had gastrointestinal or pancreatic disorders at the time of evaluation. All diagnostic procedures were conducted in the Endocrine Diagnostic Unit at the University of Maryland. After an overnight fast, each patient underwent an insulin tolerance test (8) followed by an arginine stimulation test for diagnosis of GH deficiency (8). During insulin-induced hypoglycemia blood glucose levels were followed in real time using a continuous glucose monitor $(9,10)$. Blood samples for $\mathrm{GH}, \mathrm{PP}, \mathrm{E}, \mathrm{NE}$, and cortisol were drawn at baseline at $20 \mathrm{~min}$, at glucose nadir identified in real time, and at 10 and $20 \mathrm{~min}$ after the glucose nadir. A normal GH response of $10 \mathrm{ng} / \mathrm{ml}$ to paired (insulin and arginine) stimulation and a cortisol level more than $10 \mu \mathrm{g} / \mathrm{dl}$ in response to hypoglycemia were considered normal. Each patient also had 24-h IC-GH and IC-cortisol assessment using constant blood withdrawal methodology (11, 12). The normal ranges of IC-GH and IC-cortisol for children at this age are $3.2-11.5 \mathrm{ng} / \mathrm{ml}$ and $2.7-9.1 \mu \mathrm{g} / \mathrm{dl}$, respectively (13, 14).

Assay techniques. Plasma hPP was measured by a double antibody radioimmunoassay as described by Gingerich et al. (15). Rabbit antibody to human pancreatic polypeptide, human pancreatic polypeptide standards, and labeled ${ }^{125} \mathrm{I}$-bovine $\mathrm{PP}$ with a specific activity of approximately $400-500 \mathrm{UCi} / \mu \mathrm{g}$ were kindly donated by Dr. R. E. Chance, E. Schrimer and Lilly Research Laboratories. The lowest detection limit of the assay was $10 \mathrm{pg} /$ $\mathrm{ml}$. The intra- and interassay coefficients of variation were 6 and $15 \%$, respectively.

Plasma GH was assayed using a standard double antibody technique (16). Plasma epinephrine and norepinephrine were assayed by a radioenzymatic technique $(17,18)$.

Statistical analysis. The effect of diagnostic grouping on PP, E, NE, glucose was evaluated by analysis of variance (19). Differences between means of diagnostic groups were then assessed by the method of Duncan (19). Logarithmic transformation of data was performed before statistical analysis when necessary to reduce heterogeneity of variances for parametric statistics. Regression analysis of peak hormone levels with glucose nadir was performed using standard methods (19). Data in Figures 1 and 2 and Tables 1 and 2 are expressed as mean \pm 1 SE.

\section{RESULTS}

The 31 euthyroid patients with normal cortisol secretion were subdivided into three diagnostic groups according to the following criteria. 
Control. Eleven children had normal stimulated $\mathrm{GH}$ responses and normal 24-h IC-GH

$G H N D$. Ten children had normal responses to stimulation testing but a subnormal spontaneous $24 \mathrm{IC}-\mathrm{GH}(\mathrm{GH}<3.2 \mathrm{ng} /$ $\mathrm{ml})$.

$G H D$. Ten children had subnormal $\mathrm{GH}$ responses $(\mathrm{GH}<10$ $\mathrm{ng} / \mathrm{ml}$ ) to paired stimulation testing as well as deficient IC-GH.

The ages and body mass indices ( $\mathrm{kg}$ body weight/height $\mathrm{M}^{2}$ ) and IC-cortisol for each group were similar and differences between three groups were not significant (Table 1). The differences of IC-GH among the three groups were due to selection criteria.

The effect of insulin-induced hypoglycemia on plasma PP levels in the three patient groups is shown in Figure 1. All groups had a substantial rise in plasma PP in response to hypoglycemia.

The mean PP levels became significantly higher $(p<0.001)$ than baseline at the time of the glucose nadir, and remained elevated at nadir plus 10 and nadir plus $20 \mathrm{~min}$. In 21 of 31 children, the glucose nadir preceded the maximal increase in PP by $10-20 \mathrm{~min}$. When glucose and PP responses to insulin were evaluated by diagnostic groups, short but otherwise healthy children without growth hormone deficiency (controls) exhibited a mean glucose nadir that was significantly higher $(p<0.05)$ than that observed in children with $\mathrm{GH}$ deficiency disorders (Table 2). This may be due to the fact that these non-GH-deficient patients were less sensitive to the glucose-lowering effects of insulin and thus had higher glucose nadir levels. As a consequence of higher glucose levels, controls had peak PP level and PP incremental change that were somewhat lower than the patients with GH deficiency disorders (GHND and GHD) (Table 2). However, when plasma PP levels were adjusted for glucose nadir levels there were no statistical differences between groups.

The log peak PP response was inversely correlated with the glucose nadir level $(r=-0.5, p<0.005)$. The relationship between the log peak PP and glucose nadir is shown in Figure 2.

Peak PP levels were also significantly correlated with the peak. E levels $(r=0.6, p<0.001)$. The peak NE values were not correlated with either peak PP response or the glucose nadir. The basal and peak E, NE levels were not significantly different between the groups (Table 2).

\section{DISCUSSION}

The release of $\mathrm{GH}$ is under dual control of two hypothalamic neurohormones, a stimulatory factor, $\mathrm{GH}$ releasing hormone, and an inhibitory agent, somatostatin (7). A variety of adrenergic, dopaminergic, serotoninergic, and cholinergic mechanisms participate in the regulation of these two neurohormones (7). Cholinergic and cholinergic-muscarinic blocking agents blunt $\mathrm{GH}$ response to arginine, clonidine, exercise as well as physiologic nocturnal GH secretion (5). Central vagal cholinergic mechanisms also govern the secretion of PP. We examined the possibility that defective cholinergic release of $\mathrm{GH}$ could also be related to impaired PP secretion. We found no difference in the $\mathrm{PP}$ response to hypoglycemia between normal and $\mathrm{GH}$ deficiency syndrome patients. Thus the underlying defect causing isolated GH deficiency syndromes does not impair vagal cholinergic activity as manifested by PP release.

We found that the magnitude of the log PP response was inversely related to glucose nadir levels. These results are in agreement with a previous report demonstrating a proportional increase in PP response to magnitude of glucose nadir in adults (6).

In our study the peak PP response was significantly correlated with peak E. Thus, hypoglycemia activates both sympathetic and parasympathetic nervous system activity in children. Whereas sympatheticoadrenal activation releases $\mathrm{E}$, efferent vagal parasympathetic activity leads to PP secretion $(3,20)$. PP response is unaffected by adrenalectomy (21) or by section of splanchnic nerves $(22)$ but is abolished after vagotomy $(3,19)$. A similar
Table 1. Physical characteristics and diagnostic classification of 31 children

\begin{tabular}{|c|c|c|c|c|}
\hline & Age (yr) & BMI $\left(\mathrm{kg} / \mathrm{M}^{2}\right.$ & $-G H(n g /$ & $\mathrm{IC}-\mathrm{F}(\mu \mathrm{g} / \mathrm{dl})$ \\
\hline & & & & $4.5=$ \\
\hline & & & & \\
\hline $\mathrm{HD}(n=10)$ & $12.0 \pm 0.5$ & $15.8 \pm 0.5$ & $1.9 \pm 0.2$ & $5.0 \pm 0.56$ \\
\hline
\end{tabular}

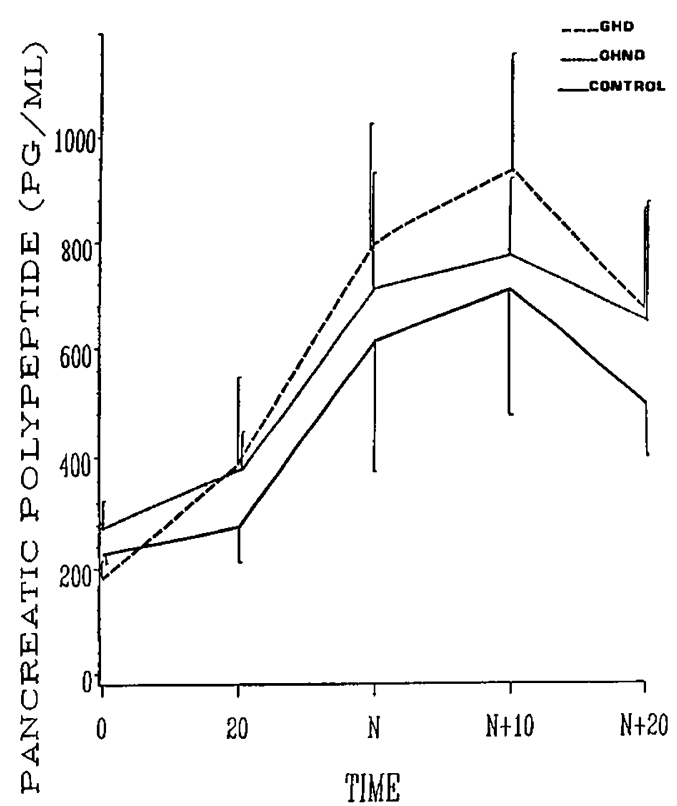

Fig. 1. Plasma PP concentrations in response to insulin-induced hypoglycemia in three diagnostic groups. Time is expressed in min: $N$, time of glucose nadir, $\mathrm{N}+10,10 \mathrm{~min}$ after the glucose nadir, $\mathrm{N}+20=20$ min after the glucose nadir.

Table 2. Basal and stimulated PP, E, NE, and glucose responses during insulin-induced hypoglycemia in children with and without growth hormone deficiency

\begin{tabular}{lccc}
\hline & $\begin{array}{c}\text { Control } \\
(n=11)\end{array}$ & $\begin{array}{c}\text { GHND } \\
(n=10)\end{array}$ & $\begin{array}{c}\text { GHD } \\
(n=10)\end{array}$ \\
\hline Glucose nadir $(\mathrm{mg} / \mathrm{dl})$ & $46 \pm 2.8$ & $37.3 \pm 2.8$ & $34.7 \pm 2^{*}$ \\
& & & \\
Pancreatic polypeptide $(\mathrm{pg} / \mathrm{ml})$ & & & \\
$\quad$ Basal & $229 \pm 27$ & $276 \pm 57$ & $190 \pm 42$ \\
$\quad$ Peak response & $747 \pm 232$ & $1110 \pm 266$ & $1042 \pm 240$ \\
Increment & $518 \pm 220$ & $843 \pm 246$ & $852 \pm 225$ \\
& & & \\
E (pg/ml) & & & \\
Basal & $72 \pm 21$ & $95 \pm 39$ & $50 \pm 10$ \\
Peak response & $639 \pm 313$ & $413 \pm 115$ & $1014 \pm 233$ \\
Increment & $566 \pm 314$ & $319 \pm 115$ & $933 \pm 242$ \\
& & & \\
NE (pg/ml) & & & \\
Basal & $264 \pm 36$ & $401 \pm 102$ & $199 \pm 26$ \\
Peak response & $373 \pm 42$ & $452 \pm 94$ & $374 \pm 39$ \\
Increment & $108 \pm 31$ & $51 \pm 27$ & $176 \pm 31$ \\
\hline
\end{tabular}

${ }^{*} p<0.05$ compared to control patients.

correlation between PP and E responses to insulin-induced hypoglycemia has been previously reported in healthy and diabetic adult subjects $(23,24)$. In contrast to these studies, Polinksy et al. (25) failed to show similar correlation in 11 adult volunteers.

We have previously reported that the $E$ and NE responses to insulin-induced hypoglycemia in children with isolated $\mathrm{GH}$ deficiency were not significantly different than the response of $\mathrm{GH}$ sufficient children (26). The present study extends these obser- 


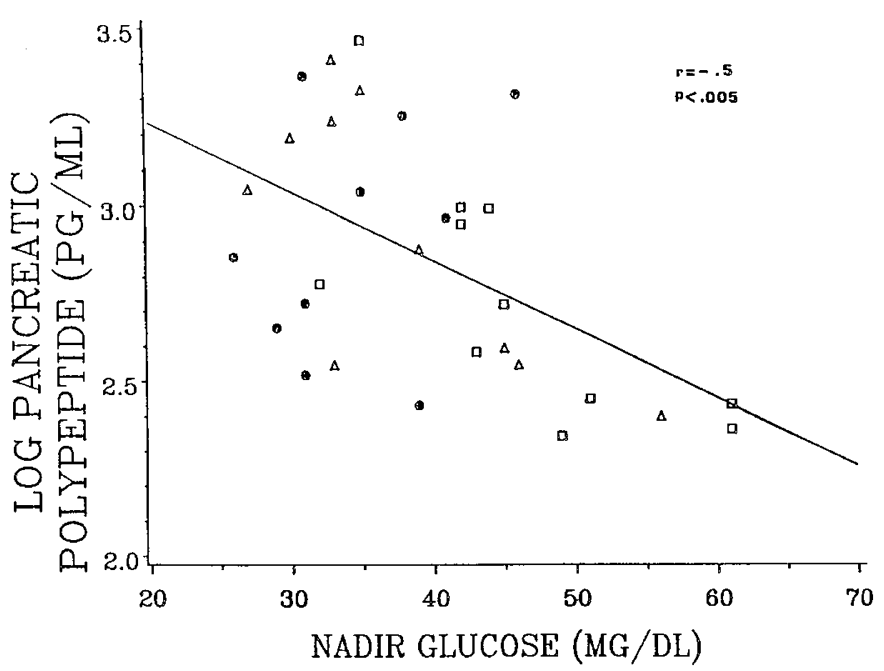

Fig. 2. Relationship between peak pancreatic polypeptide and glucose nadir in individual patients according to diagnostic grouping: $\boldsymbol{\bullet}$, growth hormone deficiency; $\Delta$, growth hormone neurosecretory deficiency; $\square$, control.

vations to the parasympathetic division of the autonomic nervous system which is not impaired in $\mathrm{GH}$ deficiency disorders.

We conclude that: 1 ) in children, hypoglycemia stimulates the peripheral release of $E$ and PP from sympathetic and parasympathetic nervous system activation, respectively and (2) vagal cholinergic and sympathetic autonomic hormone responses to hypoglycemia are unimpaired in children with $\mathrm{GH}$ deficiency syndromes.

\section{REFERENCES}

1. Locatelli V, Torsello A, Redaelli M, Ghigo E, Massara F, Muller EE 1986 Cholinergic agonist and antagonist drugs modulate the growth hormone response to growth hormone releasing hormone in the rat: evidence for mediation by somatostatin. J Endocrinol 111:271-278

2. Arends J, Wagner ML, Wilms BL 1988 Cholinergic muscarinic receptor blockade suppresses arginine- and exercise-induced growth hormone secretion in type 1 diabetic subjects. J Clin Endocrinol Metab 66:389-394

3. Adrian TE, Bloom SR, Besterman HS, Barnes AJ, Cook TJC, Russell RCG 1977 Mechanism of pancreatic polypeptide release in man. Lancet 1:161163

4. Schwartz TW 1983 Pancreatic polypeptide: a hormone under vagal control. Gastroenterology 85:1411-1425

5. Casanueva FF, Villanueva L, Cabranes JA, Cabezas-Cerrato J, FernandezCruz A 1984 Cholinergic mediation of growth hormone secretion elicited by arginine, clonidine and physical exercise in man. J Clin Endocrinol Metab
59:526-530

6. Floyd JC, Fajans SS, Pek S, Chance RE 1977 A newly recognized pancreatic polypeptide; plasma levels newly recognized pancreatic polypeptide; plasma levels in health and disease. Recent Prog Horm Res 33:519-570

7. Bercu BB, Diamond FB 1986 A determinant of stature: regulation of growth hormone secretion. In: Barness LA, Bongiovanni AM, Morrow G, Oski F, Rudolph AM (eds) Advances in Pediatrics, vol 33. Yearbook Medical Publishers, Chicago, pp 331-380

8. Raiti S, Dawis WT, Blizzard RM 1967 A comparison of the effects of insulin hypoglycemia and arginine infusion on the release of human growth hormone. Lancet 2:1182-1183

9. Hadji-Georgopoulos A, Schmidt MI, Margolis S, Kowarski AA 1980 Elevated hypoglycemic index and late hyperinsulinism in symptomatic postprandial hypoglycemia. J Clin Endocrinol Metab 50:371-376

10. Chalew SA, McLaughlin JV, Mersey JH, Adams AJ, Cornblath M, Kowarski AA 1984 The use of the plasma epinephrine response in the diagnosis of idiopathic postprandial syndrome. JAMA 251:612-615

11. Kowarski AA, Thompson RG, Migeon CJ, Blizzard RM 1971 Determination of integrated concentration of true secretion rate of human growth hormone. $\mathrm{J}$ Clin Endocrinol Metab 32:356-360

12. Zadik Z, deLacerda L, Kowarski AA 1982 Evaluation of the 6 hour integrated concentration of cortisol as a diagnostic procedure for Cushing syndrome. $\mathrm{J}$ Clin Endocrinol Metab 54:1072-1074

13. Zadik Z, Chalew SA, Raiti S, Kowarski AA 1985 Do short children secrete insufficient GH? Pediatrics 76:355-360

14. Armour KM, Chalew SA, Kowarski AA 1986 Growth impairment due to transient hypercortisolism. Acta Endocrinol [Suppl] (Copenh) 279:24

15. Gingerich RL, Lacy PE, Chance RE, Johnson MG 1978 Regional pancreatic concentration and in-vitro secretion of canine pancreatic polypeptide, insulin and glucagon. Diabetes 27:96-101

16. Schalch DS, Parker ML 1984 A sensitive double antibody immunoassay for human growth hormone in plasma. Nature 203:1141-1145

17. Peuler JD, Johnson GH 1977 Simultaneous single isotope radioenzymatic assay of plasma norepinephrine, epinephrine dopanine. Life Sci 21:625

18. Passon PG, Johnson GA 1973 A simplified radiometric assay for plasma norepinephrine and epinephrine. Anal Biochem 51:618

19. Ray AA 1982 SAS User's Guide: Statistics. SAS Institute, Cary, NC

20. Schwartz TW, Halst JJ, Fahrenkrug J, Jensen SL, Nielsen OV, Rehfeld JF, Schaffalitzky de Muckadell OB, Stradil F 1978 Vagal cholinergic regulation of pancreatic polypeptide secretion. J Clin Invest 61:781-789

21. Jarhult J, Farnebo L-O, Hamberger B, Holst JJ, Schwartz TW 1981 The relation between catecholamines, glucagon and pancreatic polypeptide during hypoglycemia in man. Acta Endocrinol 98:402-406

22. Bloom SR, Edwards AV, Hardy RN 1978 The role of the autonomic system in the control of glucagon insulin, and pancreatic polypeptide release from the pancreas. J Physiol 280:9

23. Kennedy FP, Bally GB, Go VLW, Cryer PE, Gerich JE 1987 The significance of impaired pancreatic polypeptide and epinephrine responses to hypoglycemia in patients with insulin dependent diabetes mellitus. J Clin Endocrinol Metab 64:602-608

24. White NH, Gingerich RL, Levandoski LA, Cryer PE, Santiago JV 1985 Plasma pancreatic polypeptide response to insulin induced hypoglycemia as a marker for defective glucose counterregulation in insulin dependent diabetes mellitus. Diabetes 34:870-875

25. Polinsky RJ, Taylor IL, Chew P, Weise V, Kopin IJ 1982 Pancreatic polypeptide response to hypoglycemia in chronic autonomic failure. J Clin Endocrinol Metab 54:48-52

26. Chalew SA, Kowarski AA 1986 The catecholamine response to hypoglycemia in children with isolated growth hormone deficiency syndromes and multiple pituitary hormone defects. Pediatr Res 20:1097-1101 